\title{
Introduction: Action Research for Development and Social Change
}

\author{
Danny Burns, Blane Harvey and Alfredo Ortiz Aragón*
}

\begin{abstract}
This article examines the threads that run through the seven different accounts of action research that make up this IDS Bulletin. It links the practice of action research to the power and positionality of action research facilitators. It argues that action research must explore the flows and dynamics of power in order to ensure that any changes are not superficial. It is explicit that action research involves risks and it is important to be mindful of those risks as the action research unfolds. It grounds the articles in theories of change that emphasise systemic relationships and complexity. Finally it sees learning as an iterative process in which decisions constantly have to be made about what methods to use - matching the methods specifically to the knowledge that participants want to generate at any one time.
\end{abstract}

\section{Introduction}

Participatory research and practice to achieve social change has a long history of association with the field of development. Recent years have seen significant evolutions and innovations in practice. Action Research has never been a unified approach to inquiry. It has, for example, been developed as a tool for organisational learning (e.g. Argyris and Schon 1978); and as a critical and emancipatory community learning process pioneered in the global South (e.g. Freire 1972; Fals Borda and Rahman 1991). Cooke (1998, 2003) contrasts the emancipatory associations of Participatory Action Research (PAR) with the instrumental use of Action Research as a 'tool of indirect rule' in late colonial administration. Peet and Hartwick (1999: 141) note the 'Real differences between institutional views of participation... and the more radical views of PAR theorists, who admit that their knowledge is irrelevant if local people do not regard it as useful and believe in full participation'. Beyond these questions of vision and aim lies still more diversity in process, including interpretations of forms and degrees of participation, the scope and centrality of action, and the delineation of roles within the process (Reason and Bradbury 2007).

As Participatory Research and Action Research extend to more and increasingly diverse contexts, this range of interpretations and approaches is likely to grow. As such, the contributors to this IDS Bulletin saw it as timely to reflect on both the theory and the practice of action research for development and social change, as we engage in it today. We ask ourselves, 'What do our collective understandings and experiences of, and approaches to action research have in common?', 'What can we learn from instances where these differ?' and 'What separates these approaches from other forms of social inquiry?' Furthermore, by reflecting on the use of the methods we hope to shed light on the practical implications and challenges of doing action research.

We have not sought to draw firm conclusions or a single 'theory of practice' from across these cases, but rather highlight these themes as a starting point for further discussion. What emerges from these questions is a series of recurrent themes, which provide the basis for a dialogue between the cases in this issue. The first is power. All issues and problems are located within complex power relations. Without engaging with these, the outcomes of any action research are likely to be superficial. The second is learning. Whatever the focus of our work and whichever methods and action research frameworks we bring to our work, everything we talk about in this IDS Bulletin is about learning. In this work research, policy development, 
analysis, leadership and capacity development converge and recrystallise as complex learning processes. The third is action. Effective learning cannot be abstracted from action. We take action as a result of our learning, and we learn from our action. This is why action research is so important. The fourth is an understanding of change which is rooted in systems thinking and complexity theory. In trying to understand how change happens we appreciate that the possibilities for change are the result of what is happening across a whole system or relationships, and that change is often nonlinear. Each of the articles speaks to these core concepts in different ways.

The authors of this IDS Bulletin all have different histories and relationships to action research, and we use different language. We have variously described our work as Action Learning, Action Research, Participatory Systemic Inquiry, Participatory Action Research and Systemic Action Research. These differences in approach are illustrated in the short section that follows this introduction and prefaces the other articles. The section summarises each author's individual reflections on their approach to and experience with PAR. Debates about the language used to describe action research are not unique to the authors of this IDS Bulletin, they are part of a wider debate about the meaning and definitions of participatory research. Despite our differences, what is common across all of the articles is that they describe forms of actionoriented learning and research which see participation as a core principle of engagement.

\section{Action Research and Action Learning}

Perhaps the most basic but bold claim made by action researchers is that effective learning comes through the process of trying to change things. Action is a way of knowing because life itself is conducted through action - people come to know of the world as they interact with it every day. As people work, create, stir things up, advocate, react, adapt and relate in many other ways we make sense out of life. This sensemaking combines simultaneous action and adaptive reflection as people navigate their way through real-life situations in order to survive, learn and in some cases thrive (c.f. Foley 1999).

Knowledge informs our actions, which can generate further knowledge that can inform further action - towards any human purpose. This knowledge can be put to use for practical purposes such as addressing climate change and its effects on children and communities, violence in Brazilian favelas (illegal housing settlements), community-led sanitation efforts, community engagement by universities, power relations in community and voluntary organisations, strengthening militant organisational identity, and many others. But whose and what types of action and knowledge are deemed useful in these situations? Is knowledge generated through social action primarily for local sense-making or for broader learning purposes? Should such knowledge be methodologically separated into action and research in linear cycles? How does the nature of knowledge and its relationship to action change in complex and contested social change settings? These are some of the many practical and ethical questions that are inherent to any claims to be made about the value, benefits and drawbacks, and potential winners and losers in action research processes. In this IDS Bulletin the articles use real-life experiences to address important angles of these issues.

Beyond this, action research can be framed in many different ways. Is the aim to increase efficiency or to stimulate social change? Is it to solve specific problems, challenge broader norms and assumptions, or both? One of the dilemmas that underpins many of the articles is that different stakeholders may have different answers to these questions. While facilitators may frame the action research as being about social change, it may mean different things to funders and participants. To the participants in Pettit's article (this IDS Bulletin) the process was aimed at challenging norms and framings, but for UK higher education funders in Burns' article, perhaps it was seen primarily as a problem-solving exercise.

We might also look at the focus of inquiry and learning processes themselves and the scale of change they aim to affect. Are they taking place at the individual, group, community or system level, and does action at different levels produce different types of learning and change? This is a question that has been the subject of much debate around learning and action in the past (Inglis 1997; Harvey and Langdon 2010) and different possibilities are articulated in this IDS Bulletin. The article by Pettit is focused on action 
learning and reflective practice. Individuals engage in a learning journey within a supportive group process, which they bring into their organisational and community contexts. Ortiz Aragón's work, by contrast, is centred on a process of organisational change where it is the group itself that is the focus of change. Wheeler's work, and that of Tanner and Seballos, are focused on neighbourhood communities. Wheeler worked with a group of community residents who in turn mobilised other groups within the favelas in Brazil. Tanner and Seballos worked with children in communities in the Philippines and El Salvador. Chambers describes a process of networked learning constructed around workshops. Workshops on Open Defecation are facilitated within communities, and practitioners and policymakers are networked through thematic and regional workshops. The articles by Burns and by Harvey, Burns and Oswald are operating at a system level. Here multiple inquiry strands are opened up and learning takes place across multiple collectivities. We have used these distinctions to structure the articles and start with those where the learning process is rooted in individual and group reflection, move through to processes that are working with communities and organisations, and then to some pieces of work where the focus has been on multi-stakeholder system learning.

\section{Positionality}

Building on the learning dimension articulated above, action research places all of those engaged inside the research. As Kemmis and McTaggart describe it, the best participatory action research 'Is a social process of collaborative learning realized by groups of people who join together in changing the practices through which they interact in a shared social world' (2007: 277). This means that as facilitators we not only have to consider power in the systems that we are engaging with, but we also have to acknowledge our own position with the system and the potential impacts of the power that we hold. It is not just that we (or any researchers) are not neutral but that our position has an effect on what happens within this shared social space.

In each of the cases described in this IDS Bulletin the authors have reflected on how their own positionality invariably shaped the aspects of the research process or outcomes.
My main entry-point in both field sites was prior relationships with people living within the favelas/neighbourhoods. I have worked together with these people on two previous research projects... I used to live in one of the areas studied. At the same time there are risks associated with personal relationships as entry-points because of vulnerability to exploitation and manipulation, etc. (Wheeler, this IDS Bulletin).

Our firm belief in the value of the concepts and approach [related to the learning process and the frameworks of power], and our hope of convincing certain academic and philanthropic audiences, inevitably affected the quality of the process as participatory or action research. This is the risk with processes (and articles) such as this, as we authors champion our methods with an evangelical zeal and don't reflect on our own framings and agendas. We found we had to be honest with the participants and ourselves, to question our preferences for using certain language and concepts, and to revisit our assumptions about the learning process (Pettit, this IDS Bulletin).

All of the pieces of work that we have described are supported by donors who have contracts with organisations such as the Institute of Development Studies (IDS). This can have an impact on the research. Donors may have different expectations from either facilitators or participants. For example: good work may need to develop more slowly than the donor requires; emerging issues may not stick to the core of what the donor wants to focus on; communities may want to work on issues which are not easy to measure; monitoring and evaluation systems may undermine trust and impact on what is done, and so on. Similarly participation can be distorted by a donor-facilitator-participant relationship: expectations may be formed which cannot be met; payment may be anticipated, participants may frame their inquiry or provide information that they think is expected of them by outsiders.

Our positionalities may also invite multiple, and sometimes competing, motivations for engaging in research. People who work in universities or institutes such as IDS have to generate income and write publications to remain employed. Doctoral students have a thesis to write. This can 
be problematic because facilitators need something from the process, and this can set up a very imbalanced power relationship. At one end of the spectrum communities may invest a great deal of time into processes which have little or no impact, but which are hugely beneficial to the researcher (processes which yield more in terms of professional gain for them than social, political or economic change). On the other hand, however, we have seen examples of where this issue has been surfaced explicitly and it is entirely unproblematic. People live in the real word and are aware of what others have to do in order to make things happen. Those in the Ghana Community Radio Network (Harvey, Burns and Oswald, this IDS Bulletin), for example, recognised where motivations overlapped and diverged with the research team and were relaxed about this, encouraging researchers to work on publications independently while emphasising that their focus is foremost on the production of broadcasting on the issues explored.

\section{Risk}

A number of the articles engage with issues of risk. For Wheeler, action research in the heart of the favelas can be a matter of life and death. It is crucial to ensure that the drug militias are aware and informed of the research. It is important that community researchers are clearly identified as such. Tanner and Seballos speak of the risks to children:

Although the most valuable understanding of the risks facing the lives of children in developing countries may lie with children themselves, there is a risk that exposing children to concepts and discussion about lifethreatening issues through extractive research can create feelings of helplessness, denial and disempowerment.

For Harvey, Burns and Oswald the risk lies in the systemic process. Because external facilitators and action researchers are inquiring amid potent local power relationships, there is a real danger of inadvertently transferring sensitive information from one group to another. However much we think we know as outsiders, we often don't have the tacit knowledge about power relationships, we can't read the body language that signals risk and danger. This signals the need to always work closely with people on the ground, but in doing so we must recognise the dangers of their positionality. The choice of who accompanies us will open some doors and close others, mitigate some risks and expose us and the people we are working with to others. As Wheeler points out in her account, she has the choice to leave the situation, while the people who live in the favelas have limited choices. This makes a difference. On the other hand, when the researcher analyses perhaps she analyses without fear. She may be able to speak truth to power in ways which participants cannot.

\section{Beyond methodology?}

In this IDS Bulletin we do not articulate Action Research as a methodology, although some might see it as a meta-methodology within which a variety of methods might be used. As Pettit points out, the choice of methods may be less important than how they are used, and to what ends. Traditional research methods can be powerful tools in the service of social change, and participatory methods can be co-opted and used instrumentally to reinforce the status quo. A number of the accounts of action learning and action research in this IDS Bulletin describe a mixed-method approach. An inquiry will frequently reach a point where new information is needed, and at this point participants and external facilitators will explore what methods are suitable to generate that sort of information. Children do not engage without the process being fun, so Tanner and Seballos turn their process into a race. Wheeler gives cameras to young people in the favelas because it is necessary to see through the eyes of the young people. As action researchers we believe that this is a more robust and attuned way to generate knowledge. It does not involve using a single tool for every situation, rather the researchers and participants can decide which tool is best for which job in each situation.

\section{Complexity and non-linearity}

In all of the cases shared in this IDS Bulletin the authors participated with other actors in trying to alter, improve or transform challenging situations, or at least prevent them from getting worse. Complexity theory (e.g. Stacey 2001) offers practical and theoretical explanations as to why the changes or influences we intend as action researchers and other development interveners can be so difficult to achieve. It has implications both for the issues and contexts with which we are engaged, and for the practice. 
At a basic level what we mean by complexity is that many situations in which action research facilitators and participants intervene are not straightforward, i.e. there are many actors and factors that influence the way change does or does not emerge over time, and these influences are themselves changing and unknowable in their totality. For example:

Wheeler joined with community residents to explore how violence affects community wellbeing in the historically neglected favelas of Rio de Janeiro. But although neglected by the state, these favelas receive ample attention from local militias involved in the drug trade. To even be able to reflect on community issues the researchers had to negotiate permission with these militias as well as with the participants themselves whose lives were at risk in any intervention that might challenge existing power structures. Questions of how to better understand and improve community wellbeing are heavily conditioned by these and other complex factors. Positive changes or 'results' are unknowable in advance but will emerge along the way as action researchers navigate complexity, generating action-knowledge to test the boundaries of what is possible in a high risk, violent environment.

Burns shares two action research processes: one intended to contribute to the ability of higher education institutions to better engage with local communities (and other publics), and the other to strengthen institutional and human resource capacity of 'forgotten small towns' in the Lake Victoria region of East Africa to improve the sustainability of their water and sanitation services. In the public engagement project complexity was generated from the diverse interests and world views of academics, senior managers, heads of university departments, directors of Public Engagement Beacons and university human resource managers. Each of these actors 'sees' public engagement differently, including differences in the same position but from different universities. How to improve public engagement, therefore, has no straightforward answer upfront, and indeed the answer to 'what is the public engagement problem' is not uniformly shared. The East Africa water and sanitation project also involved multiple stakeholders and interests. The research teams used a snowball process just to find out more about whom key stakeholders were, which also revealed new challenges along the way (such as why certain health centres are unable to do any preventative public health work). A 'simple' walk around the community revealed complex interests and motivations, requiring the use of relational maps that ask more questions than they provide answers, in search of patterns to help make sense out of some elements of the complexity.

Ortiz Aragón tries to help the activist organisation Program for Democracy and Global Transformation (PDTG) clarify its organisational identity but discovers through multiple reflection cycles that key elements of team-level identity are based on potentially antagonistic world views on change, on how knowledge is used to support change, and on whether the organisation is a bridge between academia and social movements, or simply a local support to social movements. Then, when external perspectives from key organisations in social movements are brought in through sociodramas (skits), the 'right' answers about what should be done to support social movements and critical academia are further blurred and depend on who you ask. This is similar to Wheeler's and Burns' cases in which complexity is generated as multiple actors with different levels of power (material and symbolic) each pursue their intentions in ways in which no one actor can control the overall patterns of behaviour that emerge.

In these and the other cases when our authors say change is non-linear and emergent we mean that outcomes result from multiple actions and interactions in ways which cannot easily be causally disaggregated, and that outcomes may look quite different from what we would expect if we aggregated all of the individual actions that people take. No one actor determines what is possible or can predict how things will actually turn out in practice. Action research can be helpful in these situations because it assumes that participants should not only act but learn their way forward - this better prepares them to make sense out of complex situations than does pure action or supposed neutral observational research. This is intended to avoid the dysfunctional divide between theorists and practitioners which, at their extreme, leaves the former ungrounded and the latter unthinking (Reeler 2007: 2). 
As more is learned about what is culturally and politically feasible and desirable from different perspectives, we can change the plan, reflect more deeply on assumptions, introduce new perspectives, and search for new ways to creatively feel our way through the marshes of complexity (Bakewell and Garbutt 2005). A plan that changes as learning emerges (rather than showing that predetermined indicators were met and the original plan stuck to) is an indicator of good action research. As Chambers points out, 'planning an output may reduce the chances of it happening'. He draws on the notion of selforganising systems on the edge of chaos (Sosotec) as a way of framing an unplanned deliberative process. In complex situations, asking better questions of those situations will often be more effective than trying to implement predefined solutions. Action research can provide tools and world views to support this sort of approach.

A number of the articles in this IDS Bulletin also challenge the orthodoxy of linear action research 'cycles'. There is something about the cycles of action research which is reassuring. By moving sequentially through the cycles of planning, acting, observing, and reflecting, a systematic method can be demonstrated which can be compared to other forms of research. The authors of this IDS Bulletin feel that this needs to be challenged. As Richard Bawden noted in a keynote speech to the 2006 Action Learning, Action Research Association (ALARA) conference these cycles are really just a series of bent straight lines, they represent a linear reasoning process as strongly as any traditional methodology. Similarly Kemmis and McTaggart (2007: 277) observe that:

In reality, the process might not be as neat as this spiral of self-contained cycles of planning, acting and observing, and reflecting suggests. The stages overlap, and initial plans quickly become obsolete in the light of learning from experience. In reality, the process is likely to be more fluid, open, and responsive. The criterion of success is not whether participants have followed the steps faithfully but rather whether they have a strong and authentic sense of development and evolution in their practices, their understandings of their practices, and the situations in which they practice.

Pettit is explicit that learning does not happen in this sequential ordered way, rather the 'Process was layered, emergent and iterative, with participants making sense of their experiences in different ways at different times'. This notion is also implicit in the parallel learning streams of the Ghana and UK/Lake Victoria processes described in the articles by Burns, and by Harvey Burns and Oswald. Here learning is happening at multiple sites in parallel, and coalesces in cross-stream learning processes.

What flows from this is the notion of extended epistemologies. Most of the articles in this IDS Bulletin build on the assumption that to understand a situation requires more than a rational analysis. This is important because if theories of change are based on an assumption of rationality then other ways of knowing and emergent opportunities for change will continually be missed. Wheeler highlights the potential of participatory video as part of a process of inquiry in her piece on Brazilian favelas; Ortiz Aragón tells a detailed story of how theatre unlocks insight, and drawing on the work of Patricia Shaw he also talks of the transformative power of conversation; Harvey, Burns and Oswald explore the power of radio. At the heart of all of this an extended approach to critical, reflective and experiential learning which is central to Pettit's piece:

If power is a multi-dimensional experience, socialised and habituated as described by the frameworks of power, then the way we learn about it needs to tap into our multiple ways of knowing. In this learning process the experiential learning cycles were present, but not over-orchestrated or managed. We aimed to create opportunities for various kinds of reflection on experience, using all the senses and feelings, including dialogue, imagery and metaphor (Pettit, this IDS Bulletin).

\section{Power}

There have been many developments of action research, but conceptually one of the most important has been the notion of double loop learning introduced by Argyris and Schon (1978). Where single loop learning looks at a problem and asks inquirers to think through solutions to the problem, double loop learning problematises the question itself. It asks us to challenge our assumptions. The assumptions that we hold frame the way that we think about issues, they crystallise into norms and routines. If assumptions are not 
critically examined in an action research process its impact is likely to be superficial.

As action researchers, we would argue that the same applies to power. If we do not understand the relations of power that encompass the issues that we are concerned about, then we will generate solutions that have little chance of success. The Ghana climate change example shows this clearly (see Harvey, Burns and Oswald, this IDS Bulletin). Without an analysis of power, it is easy to get drawn to technocratic solutions to coastal erosion such as the building of a sea wall. A sustainable holistic solution for those communities displaced by coastal erosion requires engagement with the highly political issues of land rights. Similarly a focus on power in the system of relationships within which farmers in Afiedenyigba and neighbouring communities operate indicated that a

\section{Notes}

* The authors of this introduction would like to thank their co-authors in this IDS Bulletinfor their detailed comments and contributions to

\section{References}

Argyris, C. and Schön, D. (1978) Organisational Learning, Reading MA: Addison-Wesley

Bakewell, O. and Garbutt, A. (2005) The Use and Abuse of the Logical Framework Approach, Stockholm: Swedish International Development Cooperation Agency (SIDA)

Cooke, B. (2003) 'A New Continuity with Colonial Administration: Participation in Development Management', Third World Quarterly 24.1: 47-61

Cooke, B. (1998) 'Participation, "Process" and "Management": Lessons for Development in the History of Organization Development', Journal of International Development 10.1: 35-54

Fals Borda, O. and Rahman, M. (eds) (1991) Action and Knowledge: Breaking the Monopoly with Participatory Action Research, New York: Apex

Foley, G. (1999) Learning in Social Action: A Contribution to Understanding Informal Education, New York: St Martin's Press

Freire, P. (1972) Pedagogy of the Oppressed, London: Penguin fundamental problem lay in the power of a privileged few to regulate prices, etc. Power lies in the relationships between stakeholders, but it also lies in the way in which these relationships lock into powerful system dynamics, and in the subtle ways in which power is embedded in social norms and embodied in habitual behaviour. All of these manifestations of power are explored in the articles.

\section{Conclusions}

The articles in this IDS Bulletin raise complex questions about the relationship between action research, development and social change. They are a contribution to a debate which we are keen to take much further. We would like them to stimulate an interactive dialogue which we propose to open up on the blog $\operatorname{site}^{1}$ of the Participation, Power and Social Change Team at the IDS. We warmly invite you to participate.

this article: Robert Chambers, Jethro Pettit, Katy Oswald, Frances Seballos, Thomas Tanner, and Joanna Wheeler.

1 See http://participationpower.wordpress.com/.

Harvey, B. and Langdon, J. (2010) 'Re-imagining Capacity and Collective Change: Experiences from Senegal and Ghana', IDS Bulletin 41.3, Brighton: IDS

Inglis, T. (1997) 'Empowerment and Emancipation', Adult Education Quarterly 48.1: 3-17

Kemmis, S. and McTaggart, R. (2007) 'Participatory Action Research:

Communicative Action and the Public Sphere', in N. Denzin and Y. Lincoln, Strategies of Qualitative Inquiry, 3rd edition, London: Sage Publishers: 271-330

Peet, R. and Hartwick, E. (1999) Theories of Development, New York and London: Guilford Press

Reason, P. and Bradbury, H. (2007) Handbook of Action Research, 2nd edition, London: Sage

Reeler, D. (2007) A Theory of Social Change and Implications for Practice, Planning, Monitoring and Evaluation, Cape Town: Community Development Resource Association (CDRA)

Stacey, R. (2001) Complex Responsive Processes in Organisations, London: Routledge 